\title{
Reproductive Factors and Risk of Breast Cancer by Tumor Subtypes among Ghanaian
}

\section{Women: A Population-based Case-control Study}

Jonine D Figueroa ${ }^{1,2, \#}$, Brittny C Davis Lynn ${ }^{1 \#}$, Lawrence Edusei ${ }^{3}$, Nicholas Titiloye ${ }^{4}$, Ernest Adjei ${ }^{4}$, Joe-Nat Clegg-Lamptey ${ }^{3}$, Joel Yarney ${ }^{3}$, Beatrice Wiafe-Addai ${ }^{5}$, Baffour Awuah $^{4}$, Maire A. Duggan ${ }^{6}$, Seth Wiafe ${ }^{7}$, Kofi Nyarko ${ }^{8}$, Francis Aitpillah ${ }^{4}$, Daniel Ansong ${ }^{4}$, Stephen M Hewitt ${ }^{9}$, Thomas Ahearn ${ }^{1}$, Montserrat Garcia-Closas ${ }^{1, \# *}$ and Louise A Brinton ${ }^{1 \#,}$ on behalf of the Ghana Breast Health Study team

"These authors contributed equally

${ }^{1}$ Division of Cancer Epidemiology and Genetics, National Cancer Institute, Bethesda, MD, USA; ${ }^{2}$ Usher Institute and CRUK Edinburgh Centre, University of Edinburgh, Edinburgh, UK; ${ }^{3}$ Korle Bu Teaching Hospital, Accra, Ghana; ${ }^{4}$ Komfo Anokye Teaching Hospital, Kumasi, Ghana; ${ }^{5}$ Peace and Love Hospital, Kumasi, Ghana; ${ }^{6}$ Department of Pathology and Laboratory Medicine, University of Calgary, Calgary, Canada ${ }^{7}$ Loma Linda University, School of Public Health, Loma Linda, CA, USA; ${ }^{8}$ University of Ghana, Accra, Ghana;

${ }^{9}$ Center for Cancer Research, National Cancer Institute, Bethesda, MD, USA

*Corresponding Authors:

MGC: National Cancer Institute, Division of Cancer Epidemiology \& Genetics

Office of the Director

NCI Shady Grove

Phone: +1-240-276-7150

E-mail: montserrat.garcia-closas@nih.gov

JDF: Usher Institute, University of Edinburgh

Teviot Place, Room 3.736A 
medRxiv preprint doi: https://doi.org/10.1101/19006833; this version posted November 27, 2019. The copyright holder for this preprint (which was not certified by peer review) is the author/funder, who has granted medRxiv a license to display the preprint in perpetuity.

This article is a US Government work. It is not subject to copyright under 17 USC 105 and is also made available for use under a CCO license.

Phone: +44 (0)131 6514140

Email: jonine.figueroa@ed.ac.uk

\section{List of abbreviations:}

ER: estrogen receptor

OR: odds ratios

CI: confidence interval

PR: progesterone receptor

HER2: human epidermal growth factor receptor 2

AMBER: African American Breast Cancer Epidemiology and Risk

IHC: immunohistochemical

NCI: National Cancer Institute

ABCS: African Breast Cancer Study 


\section{Abstract \\ Background}

Higher proportions of early-onset and estrogen receptor (ER) negative cancers are observed in women of African ancestry than in women of European ancestry. Differences in risk factor distributions and associations by age at diagnosis and ER status may explain this disparity.

\section{Methods}

We analyzed data from 1,126 women (aged 18-74 years) with invasive breast cancer and 2,106 population controls recruited from three hospitals in Ghana from 2013 to 2015. Odds ratios $(\mathrm{OR})$ and $95 \%$ confidence intervals $(\mathrm{CI})$ were estimated for menstrual and reproductive factors using polytomous logistic regression models adjusted for potential confounders.

\section{Results}

Among controls, medians for age at menarche, parity, age at first birth, and breastfeeding/pregnancy were 15 years, 4 births, 20 years, and 18 months, respectively. For women $\geq 50$ years, parity and extended breastfeeding were associated with decreased risks: $>5$ births vs. nulliparous, OR 0.40 (95\% CI 0.20-0.83) and 0.71 (95\% CI 0.51-0.98) for $\geq 19$ vs. $<13$ breastfeeding months/pregnancy, which did not differ by ER. In contrast, for earlier onset cases $(<50$ years $)$ parity was associated with increased risk for ER-negative tumors $(P$ heterogeneity by ER $=0.02$ ), which was offset by extended breastfeeding. Similar associations were observed by intrinsic-like subtypes. Less consistent relationships were observed with ages at menarche and first birth.

\section{Conclusion}

Reproductive risk factor distributions are different from European populations but exhibited etiologic heterogeneity by age at diagnosis and ER status similar to other populations. 
Differences in reproductive patterns and subtype heterogeneity are consistent with racial disparities in subtype distributions.

Keywords: Reproductive risk factors, subtype heterogeneity, racial disparities, breast cancer

\section{Key Messages}

- Distribution of intrinsic-like breast cancer subtypes among Ghanaian women are distinct compared to European ancestry populations, with a higher proportion of ERnegative subtypes at younger ages.

- Increasing number of births and extended breastfeeding were associated with reduced risk for both ER-positive and ER-negative subtypes among later-onset breast cancer cases (women age $\geq 50$ years).

- Extended breastfeeding offset a direct association that we observed of multiparity with early-onset (women age $<50$ years) ER-negative breast cancers.

- Number of births and breastfeeding duration are much higher in Ghanaian women compared to women of European ancestry and African Americans, however the relationships with risk are consistent when assessed by molecular subtype. 


\section{Introduction}

Reproductive factors have been well documented as key breast cancer risk factors with direct associations observed with early ages at menarche, nulliparity, late ages at first birth and limited breastfeeding. Breast cancer is a heterogeneous disease, with differential etiologic associations for tumor subtypes defined by estrogen receptor (ER), progesterone receptor (PR) and human epidermal growth factor receptor 2 (HER2) status.(1) Most of these results derive from studies on European ancestry populations. Similar investigations among African ancestry populations are crucial given the differences in demographic and risk factor distributions and their disproportionately high incidence of early-onset breast cancer and ERnegative aggressive subtypes.(1-4)

Analyses of risk factors by the African American Breast Cancer Epidemiology and Risk (AMBER) consortium have revealed differential risk factor associations by tumor subtypes defined by ER, PR, and HER2 status.(5,6) Parity was associated with a decreased risk for ER-positive cancers but an increased risk for triple-negative breast tumors; furthermore, ever breastfeeding in parous women was strongly inversely related to the risk of triple-negative tumors.(6) Accumulating data support similar observations in other studies on women of African American and European ancestry, although distributions of risk factors differ.(1,711)

With substantially increasing rates of breast cancer in sub-Saharan Africa, identifying risk factors and strategies for reducing incidence are essential.(12,13) A population-based casecontrol study of breast cancer in Ghana aimed to overcome challenges of previous African studies that were unable to select population-based controls and properly classify hormone receptor-negative cases. $(3,12,14,15)$ Using a census-based sampling of controls (16) and standardized protocols for collecting tumor biopsy samples for immunohistochemical (IHC) 
staining from cases prior to treatment (17), we sought to determine the associations between menstrual and reproductive risk factors and breast cancer subtypes.

\section{Methods}

See Supplemental Material for further details on methods for study population, risk factor information, ethical approvals, tumor characteristics, and statistical analysis.

\section{Study population}

Details of the multi-disciplinary population-based case-control study in Ghana have been previously described.(17-18, 22 ) Our primary analyses focused on ER status because this was the key marker of etiological heterogeneity demonstrated in previous studies.(19)

\section{Statistical analysis}

Odds ratios (ORs) and 95\% confidence intervals (95\% CIs) were estimated to determine menstrual and reproductive factors using polytomous logistic models adjusted for study site and age (as a categorical variable) as well as key risk factors, including education, a family history of breast cancer, body size (17) and menopausal status or age at menopause. All statistical tests were two-sided. Analyses were performed using STATA/MP 14.2 (StataCorp, College Station, TX). Plots on the means and standard deviations of a 3-point running average were obtained using $\mathrm{R}$ version 3.4.4.

\section{Results}


medRxiv preprint doi: https://doi.org/10.1101/19006833; this version posted November 27, 2019. The copyright holder for this preprint (which

was not certified by peer review) is the author/funder, who has granted medRxiv a license to display the preprint in perpetuity.

This article is a US Government work. It is not subject to copyright under 17 USC 105 and is also made available for use under a CCO license.

Descriptive characteristics of cases and controls

Cases were slightly older than controls reflecting that the controls were initially frequency matched to all women with a suspicion of breast cancer prior to diagnosis confirmation. Approximately half of these women had non-malignant breast diseases and tended to be younger than those with malignant breast disease.(17) The cases more often than the controls reported late ages at menarche, few births, late ages at first birth and low median breastfeeding months (Table 1).

(Table 1 here)

A total of $50 \%, 52 \%$ and $23 \%$ of cases were ER positive, PR positive, and HER2 positive, respectively (Table 1). Luminal A-like breast cancer was the most common subtype (49\%) followed by triple-negative/basal-like (28\%), HER2-enriched (15\%) and luminal B-like breast cancers (8\%) (Fig. 1). There were no significant differences in cases missing ER, PR and HER2 status by risk factor data (data not shown).

We assessed descriptively if reproductive factors varied by birth cohort (1945-1975), which are presented in Fig. 2. Number of births was lower in later birth cohorts compared to earlier birth cohorts, with cases having fewer births on average compared with the controls (1945, mean 4.1 for cases and 6.4 for controls; 1975 , mean 2.5 for cases and 3.3 for controls). Age at first birth increased by approximately 1 year in the later compared with earlier birth cohorts for both cases and controls (21.7 in 1945 and 22.3 in 1975 among controls). Age at menarche showed no apparent trends, hovering around 15 years across the birth cohorts. Breastfeeding months per pregnancy among controls declined until the 1960s and steadily increased until 
1975. Among the cases, breastfeeding months per pregnancy increased over time by 1 month per pregnancy from 17 to 18 months.

Associations with reproductive factors overall and stratified by age

Associations for age at menarche, number of births, age at first birth, and median breastfeeding months per pregnancy overall and stratified by age are shown in Table 2. Analyses of all cases combined showed number of births as the only risk factor with a statistically significant risk association $(P$-trend=0.005). Among women aged $<50$ years, we observed an inverse association with parity ( $\geq 5$ vs 0 births: OR $0.70,95 \%$ CI $0.42-1.18, P$ trend $=0.06)$ and an increased risk with older ages at first birth $(\geq 26$ vs $<19$ years: OR 1.40, 95\% CI 0.97-2.01, $P$-trend $=0.05)$. In more discrete categories of age, we observed a significant trend $(P=0.01)$ with advancing age at first birth among women aged $<40$ years (Supplementary Table 1). Age at menarche and median breastfeeding months were not significantly associated with breast cancer risk among younger women. Among women aged $\geq 50$ years, a strong inverse association was observed with parity ( $\geq 5$ vs 0 births: OR 0.40 , 95\% CI 0.20-0.83); a test for interaction with age was significant $(P=0.02)$. Similarly, median breastfeeding months among older women were inversely associated with risk $(\geq 19$ vs $<13$ months: OR $0.71,95 \%$ CI $0.51-0.98$ ) and demonstrated a significant interaction with age $(P=0.01)$. Age at menarche was unrelated to risk among the older women (Table 2).

Evaluation of these associations with more detailed categories of age revealed a significant interaction by age for parity and median breastfeeding months per pregnancy, with the strongest inverse associations of parity and extended breastfeeding among women aged $\geq 60$ years (Supplementary Table 1).

(Table 2 here) 
medRxiv preprint doi: https://doi.org/10.1101/19006833; this version posted November 27, 2019. The copyright holder for this preprint (which

was not certified by peer review) is the author/funder, who has granted medRxiv a license to display the preprint in perpetuity.

This article is a US Government work. It is not subject to copyright under 17 USC 105 and is also made available for use under a CCO license.

Associations with reproductive factors by ER and stratified by age

Analyses for all cases combined did not show statistically significant differences for ER-negative compared with ER-positive cases (Supplementary Table 2). When we evaluated the associations by ER status among women aged $<50$ years (Table 3 ), we observed a strong inverse association with parity for ER-positive tumors and a positive association for ERnegative tumors, with the test for heterogeneity being statistically significant $(P$-het $=0.02)$. Among women $<50$ years, older ages at first birth showed a slightly stronger association with increased risk for ER-positive than ER-negative breast tumors, but the test for heterogeneity was not statistically significant. Extended breastfeeding only showed an inverse association among ER-negative tumors, with evidence of significant heterogeneity compared with ERpositive tumors ( $\geq 19$ vs $<13$ months: ER-positive tumors OR 1.39, 95\% CI 0.82-2.34; ERnegative tumors $0.71,0.45-1.12 ; P$-het $=0.04)$. There was no additional relationship for $\geq 19$ breastfeeding months; when we compared women with $\geq 13$ breastfeeding months per pregnancy to $<13$ months, the resultant OR for ER-negative tumors was OR 0.69 (95\% CI 0.45-1.03). There was a suggestion of a positive association with older ages at menarche for ER-positive breast tumors that was not apparent for ER-negative breast tumors.

(Table 3 here)

Among the women aged $\geq 50$ years (Table 4), parity was inversely associated with risk for both ER-negative and ER-positive tumors (although there were few nulliparous women, p-het $=0.33)$. Although extended breastfeeding showed an inverse association regardless of ER 
status, a stronger association was observed among ER-positive tumors $(P$-het $=0.07)$. Age at first birth did not demonstrate any consistent associations with risk.

(Table 4 here)

We further assessed the joint effects of parity and breastfeeding per pregnancy (Fig. 3). Among women aged $\geq 50$ years, increasing parity, and breastfeeding were associated with reduced risks for both ER-negative and ER-positive tumors, with the lowest risks observed among women with $\geq 3$ births who breastfed for $\geq 13$ months/pregnancy compared with nulliparous women (ER-negative cases: OR 0.45, 95\% CI 0.21-0.95; ER-positive cases: OR $0.31,95 \%$ CI $0.13-0.75)$. This trend was less apparent among women aged $<50$ years with ER-positive tumors $[\geq 3$ births who breastfed for $\geq 13$ months/pregnancy compared with nulliparous women (OR 0.69, 95\% CI 0.36-1.30)]. In contrast, among women aged $<50$ years with ER-negative tumors, compared with nulliparous women, the highest risk was for those with $\geq 3$ births who breastfed $<13$ months/pregnancy (OR 1.91, 95\% CI 0.89-4.10). Women with $\geq 3$ births who breastfed, on average, $\geq 13$ months per pregnancy were not at increased risk (OR 1.09, 95\% CI 0.56-2.10), due to the multiplicative joint association of two factors associated with risk in opposite directions.

Associations with reproductive factors by ER, PR, HER2 status and stratified by age

We evaluated if associations with parity and breastfeeding differed using the IHC proxy for intrinsic subtypes. We focused our analyses on triple-negative compared with luminal A-like cases because previous studies have shown differences between these two 
groups $(6-9,20,21)$ and these were also the two most common tumor subtypes

(Supplementary Tables 3-4). Parity was inversely related to the risk of luminal A-like tumors regardless of age, as well as with risk of triple-negative tumors among women aged $\geq 50$ years (Supplementary Tables 3-4). In contrast, a positive association was observed for triplenegative tumors among women aged $<50$ years $(P$-het $=0.03)$. Among younger women with triple-negative tumors, extended breastfeeding was inversely associated with risk, a relationship not observed for luminal A-like tumors. In contrast, among older women, we observed a strong inverse association of breastfeeding with luminal A-like tumors (OR 0.52, 95\% CI 0.33-0.82) that was not observed for triple-negative tumors $(P$-het $=0.04)$ (Supplementary Table 4).

\section{Discussion}

Among Ghanaian women, we observed substantial heterogeneity of the parity association with breast cancer risk by age at diagnosis and ER status, with strong inverse associations for all tumor subtypes in older ( $\geq 50$ years) women and for younger-onset ERpositive tumors, but an opposite association for younger-onset ER-negative tumors (i.e. increased risk with increasing birth numbers). Median breastfeeding months per pregnancy was strongly inversely associated with later-onset breast tumor risk (particularly ER-positive or luminal A-like tumors); among younger women, it was an apparent protective factor for ER-negative tumors only. Similar to previous reports, $(6-9,20,21)$ our study population allowed an evaluation of associations for a wide range of number of births and breastfeeding months per pregnancy.

Few studies have addressed the relation of reproductive risk factors in women of African ancestry. The largest dataset derives from the African Breast Cancer Study (ABCS),(22) a hospital-based case-control study in Nigeria, Cameroon and Uganda, comprising 1,995 cases 
medRxiv preprint doi: https://doi.org/10.1101/19006833; this version posted November 27, 2019. The copyright holder for this preprint (which

was not certified by peer review) is the author/funder, who has granted medRxiv a license to display the preprint in perpetuity.

This article is a US Government work. It is not subject to copyright under 17 USC 105 and is also made available for use under a CCO license.

and 2,631 controls (with $81 \%$ of the cases from Nigeria). Analyses from this study showed changing reproductive patterns over time (particularly number of births) and an inverse association of risk with parity; however, it did not show statistically significant heterogeneity of risk associations by menopausal status or age at diagnosis. $(22,23)$ Notably, in contrast to our study, ABCS was not population-based and lacked information on hormone receptor status of the tumors, thereby limiting the comparability of the findings. Data from the AMBER consortium, a pooled analysis of four studies of African-American women with available tumor IHC data found that among 1,252 ER-negative breast tumors parous women were at elevated risk compared with nulliparous women, increasing to 1.60 among those aged $<40$ years.(6) Our data are consistent with AMBER and other recent studies, $(9,11)$ supporting a cross-over association between parity on breast cancer risk that is dependent on age at onset and ER status.

In our Ghanaian population, number of births and breastfeeding years were highly correlated. Our data showed a significant inverse risk relationship with median breastfeeding months per pregnancy, with a $15 \%$ reduced risk for those with $13-18$ vs $<13$ months/pregnancy. In pooled analyses of populations of European ancestry, breastfeeding has been shown to have a weak inverse association with breast cancer risk. However, recent data that includes molecular subtyping information provides evidence of a possible stronger inverse association for hormone-negative breast tumors.(6-9,20,21) In the AMBER study, the inverse association of breastfeeding was most pronounced for younger-onset ER-negative and triple-negative breast tumors. In fact, for such tumors, analyses demonstrated that extended breastfeeding could reduce the adverse risks associated with parity, which has also been seen in other studies that included African-American women.(9,11) Our results revealed similar associations given that extended breastfeeding appeared to largely counteract the adverse relationship with multiparity among younger women with ER-negative tumors. 
Recent studies assessing associations by molecular subtypes using IHC and mRNA expression profiling have shown increased risk with parity that may predominate for triplenegative or basal-like breast tumors. $(20,24)$ In our study, the modifications in risk associations between parity and breastfeeding by age reflected different temporal trend patterns by birth cohorts in cases and controls: the rate of decrease in number of births was faster for controls than cases in early birth cohorts (i.e., older women); a decreasing trend of breastfeeding months per pregnancy in early birth cohorts was seen in controls but not in cases. Given that multiparity and increased breastfeeding are inversely associated with lateronset breast cancers (with somewhat stronger associations with ER-positive tumors), if the observed temporal trends of decreasing parity and breastfeeding continue, they are likely to result in an increased incidence of later-onset breast cancer.(13) This indicates the importance of public health measures to maintain high rates of breastfeeding,(25) which could potentially attenuate the projected increase in risk due to changes in reproductive patterns and demographics.(13,26)

Older age at first birth has been associated with increases in breast cancer risk in numerous studies, particularly for ER-positive tumors. $(8,10,20,27,28)$ The AMBER consortium also found increased risks for older ages at first birth for ER-positive but not for ER-negative tumors. Our data were consistent with these findings, suggesting that this association may be stronger or limited to early-onset ER-positive breast cancer cases.(6) However, in African populations, this is a difficult exposure to assess given that few women actually delay their first births until truly late ages. With increasing adoption of westernized lifestyles and access to birth control, continued monitoring of maternity data are needed to determine if ages at first birth continue to increase. 
In spite of the observed trends in reproductive patterns toward westernization, our study population still maintained higher parity and breastfeeding frequencies compared with other populations. The reproductive patterns in our study are consistent with recent nationally representative surveys. $(29,30)$ For example, the decline in fertility rate from 6.4 in 1988 to 3.9 in 2017 reported in surveys by the Ghana Maternal Health Survey ages 15-49 years is similar to the decline in average number of live births in our control population from 6.4 to 3.3 for women born in 1945 (i.e. 43 years old in 1988) and 1975 (i.e. 42 years old in 2017).(29) Median breastfeeding months per pregnancy were 17 to 18 months in our study controls and in a 2011 survey median months breastfeeding were 17.4 and 17.9 months for Greater Accra and Ashanti regions, respectively.(30) The strong inverse associations of these factors with late onset, mostly ER-positive tumors, together with a lack of population-based screening, are likely important factors contributing to historically low incidence of late onset ER-positive breast cancers. In contrast, for early-onset cancers, higher parity was directly associated with ER-negative disease in our study. It is doubtful, however, that high parity explains the higher incidence of ER-negative early-onset cancers in our population given the high prevalence of breastfeeding, which appeared to offset the higher risk from multiparity. Instead, the younger demographics in Ghana and other sub-Saharan African countries probably explains the higher proportion of these early-onset cancers compared with populations of European ancestry.(3) It may be that rather than a population with an "excess" of early-onset ER-negative cancers that there could be fewer diagnoses of late onset ERpositive breast cancer compared with other populations, as suggested in other studies.(31) To specifically address this, further studies comparing age- incidence rates of breast cancer subtypes in Africa are needed, similar to U.S. studies that have addressed racial differences by age.(32) 
Age at menarche has been inversely associated with risk in European ancestry populations.(33) In the studies of African-American women, later ages at menarche were inversely associated with breast cancer regardless of hormone receptor status.(5,9) In contrast, we observed no such relationship. The median age of menarche of 15 years in Ghanaian women is quite different from the reported age of 12 years among AfricanAmerican women, with our study having limited variation in ages at menarche. Increased nutrition has been suggested to lower the age at menarche; this variable could reflect early exposures that may differ between populations (e.g. early adolescent weight).(34) In addition, a substantial number of women in our study could not recall their ages at menarche, suggesting that measurement error could have impacted our ability to assess relationships reliably.

Strengths of this study are the population-based design, detailed risk factor assessment, and tissue collection for quality assessment of IHC markers to examine etiologic heterogeneity in sub-Saharan Africa. A limitation is that although IHC data can be used as a proxy for molecular subtypes, mRNA expression assays are required to classify previously described intrinsic molecular subtypes, especially HER2-enriched and luminal B subtypes. Further, although our study is one of the largest breast cancer epidemiological studies conducted in sub-Saharan Africa, analyses by age and subtypes resulted in small numbers within strata of these critical factors.

Our study indicates that while reproductive factors showed important temporal trends and distinct distributions compared with African-American or European ancestry populations, their associations with breast cancer risk were generally consistent with those observed in these populations. Our data support the importance of breastfeeding to prevent early-onset ER-negative breast cancer associated with multiparty and the longer-term protection of parity 
and breastfeeding for later-onset breast tumors, irrespective of their ER status. Further studies including more detailed molecular characterization of tumors and additional risk factors may provide additional insights into breast cancer etiology in sub-Saharan Africa.

\section{Funding}

This work was supported by Intramural program of the National Cancer Institute.

\section{Acknowledgments}

We are grateful to all women who agreed to participate in the study and provided information and biospecimens.

\section{Author contributions}

Conception \& Design of the study: JDF, BDL, LE, NT, EA, JNCL, JY, BW, BA, MD, SW, KN, FA, DA, SH, TA, MGC, LAB; Data collection: JDF, BDL, LE, NT, EA, JNCL, JY, BW, BA, MD, SW, KN, FA, DA, SH, TA, MGC, LAB; Interpretation of data JDF, BDL, LE, NT, EA, JNCL, JY, BW, BA, MD, SW, KN, FA, DA, SH, TA, MGC, LAB; Drafting of the manuscript: JDF, BDL, LAB, MGC; Revised work and provided important intellectual content: JDF, BDL, LE, NT, EA, JNCL, JY, BW, BA, MD, SW, KN, FA, DA, SH, TA, MGC, LAB.

\section{Conflict of Interest: none declared}

\section{Ghana Breast Health Study team}

Ghana Statistical Service, Accra, Ghana: Dr Robertson Adjei and Dr Lucy Afriyie. Korle Bu Teaching Hospital, Accra, Ghana: Dr Anthony Adjei, Dr Florence Dedey, Dr Verna Vanderpuye, Victoria Okyne, Naomi Ohene Oti, Evelyn Tay, Dr Adu-Aryee, Angela Kenu and Obed Ekpedzor. Komfo Anoyke Teaching Hospital, Kumasi, Ghana: Marion Alcpaloo, Isaac Boakye, Bernard Arhin, Emmanuel Assimah, Samuel Ka-chungu, Dr Joseph Oppong 
medRxiv preprint doi: https://doi.org/10.1101/19006833; this version posted November 27, 2019. The copyright holder for this preprint (which

was not certified by peer review) is the author/funder, who has granted medRxiv a license to display the preprint in perpetuity.

This article is a US Government work. It is not subject to copyright under 17 USC 105 and is also made available for use under a CCO license.

and Dr Ernest Osei-Bonsu. Peace and Love Hospital, Kumasi, Ghana: Prof Margaret

Frempong, Emma Brew Abaidoo, Bridget Nortey Mensah, Samuel Amanama, Prince

Agyapong, Debora Boateng, Ansong Thomas Agyei, Richard Opoku and Kofi Owusu

Gyimah. Memorial Sloan Kettering Cancer Center, NY, USA: Dr Lisa Newman. National

Cancer Institute, Bethesda, MD, USA: Maya Palakal and Jake Thistle. Westat, Inc.: Michelle

Brotzman, Shelley Niwa, Usha Singh and Ann Truelove. University of Ghana: Prof Richard

Biritwum. 


\section{References}

1. Anderson KN, Schwab RB, Martinez ME. Reproductive risk factors and breast cancer subtypes: a review of the literature. Breast Cancer Res Treat. 2014; 144:1-10.

2. Ademuyiwa FO, Tao Y, Luo J, Weilbaecher K, Ma CX. Differences in the mutational landscape of triple-negative breast cancer in African Americans and Caucasians. Breast

Cancer Res Treat. 2017; 161:491-499.

3. Brewster AM, Chavez-MacGregor M, Brown P. Epidemiology, biology, and treatment of triple-negative breast cancer in women of African ancestry. Lancet Oncol. 2014; 15:e625-34.

4. Newman LA, Kaljee LM. Health Disparities and Triple-Negative Breast Cancer in African American Women: A Review. JAMA Surg. 2017; 152:485-493.

5. Ambrosone CB, Zirpoli G, Hong CC, et al. Important Role of Menarche in Development of Estrogen Receptor-Negative Breast Cancer in African American Women. J Natl Cancer Inst. 2015; 107.

6. Palmer JR, Viscidi E, Troester MA, et al. Parity, lactation, and breast cancer subtypes in African American women: results from the AMBER Consortium. J Natl Cancer Inst. 2014; 106.

7. Fortner RT, Sisti J, Chai B, et al. Parity, breastfeeding, and breast cancer risk by hormone receptor status and molecular phenotype: results from the Nurses' Health Studies. Breast Cancer Res. 2019; 21:40.

8. Gaudet MM, Gierach GL, Carter BD, et al. Pooled Analysis of Nine Cohorts Reveals Breast Cancer Risk Factors by Tumor Molecular Subtype. Cancer Res. 2018; 78:6011-6021. 9. Ma H, Ursin G, Xu X, et al. Reproductive factors and the risk of triple-negative breast cancer in white women and African-American women: a pooled analysis. Breast Cancer Res. 2017; 19:6. 
10. Lambertini M, Santoro L, Del Mastro L, et al. Reproductive behaviors and risk of developing breast cancer according to tumor subtype: A systematic review and meta-analysis of epidemiological studies. Cancer Treat Rev. 2016; 49:65-76.

11. John EM, Hines LM, Phipps AI, et al. Reproductive history, breast-feeding and risk of triple negative breast cancer: The Breast Cancer Etiology in Minorities (BEM) study. Int J Cancer. 2018; 142:2273-2285.

12. Akarolo-Anthony SN, Ogundiran TO, Adebamowo CA. Emerging breast cancer epidemic: evidence from Africa. Breast Cancer Res. 2010; 12 Suppl 4:S8.

13. Torre LA, Bray F, Siegel RL, Ferlay J, Lortet-Tieulent J, Jemal A. Global cancer statistics, 2012. CA Cancer J Clin. 2015; 65:87-108.

14. Bird PA, Hill AG, Houssami N. Poor hormone receptor expression in East African breast cancer: evidence of a biologically different disease? Ann Surg Oncol. 2008; 15:19831988.

15. Brinton LA, Figueroa JD, Awuah B, et al. Breast cancer in Sub-Saharan Africa: opportunities for prevention. Breast Cancer Res Treat. 2014; 144:467-478.

16. Nyante SJ, Biritwum R, Figueroa J, et al. Recruiting population controls for casecontrol studies in sub-Saharan Africa: The Ghana Breast Health Study. PLoS One. 2019; 14:e0215347.

17. Brinton LA, Awuah B, Nat Clegg-Lamptey J, et al. Design considerations for identifying breast cancer risk factors in a population-based study in Africa. Int J Cancer. 2017; 140:2667-2677.

18. Brinton L, Figueroa J, Adjei E, et al. Factors contributing to delays in diagnosis of breast cancers in Ghana, West Africa. Breast Cancer Res Treat. 2017; 162:105-114.

19. Allred DC, Brown P, Medina D. The origins of estrogen receptor alpha-positive and estrogen receptor alpha-negative human breast cancer. Breast Cancer Res. 2004; 6:240-245. 
20. Holm J, Eriksson L, Ploner A, et al. Assessment of Breast Cancer Risk Factors

Reveals Subtype Heterogeneity. Cancer Res. 2017; 77:3708-3717.

21. Work ME, John EM, Andrulis IL, et al. Reproductive risk factors and

oestrogen/progesterone receptor-negative breast cancer in the Breast Cancer Family Registry.

Br J Cancer. 2014; 110:1367-1377.

22. Sighoko D, Ogundiran T, Ademola A, et al. Breast cancer risk after full-term

pregnancies among African women from Nigeria, Cameroon, and Uganda. Cancer. 2015.

23. Huo D, Adebamowo CA, Ogundiran TO, et al. Parity and breastfeeding are protective against breast cancer in Nigerian women. Br J Cancer. 2008; 98:992-996.

24. Sun X, Nichols HB, Tse CK, et al. Association of parity and time since last birth with breast cancer prognosis by intrinsic subtype. Cancer Epidemiol Biomarkers Prev. 2016;

25:60-67.

25. Victora CG, Bahl R, Barros AJ, et al. Breastfeeding in the 21st century: epidemiology, mechanisms, and lifelong effect. Lancet. 2016; 387(10017):475-490.

26. Tamimi RM, Spiegelman D, Smith-Warner SA, et al. Population attributable risk of modifiable and nonmodifiable breast cancer risk factors in postmenopausal breast cancer. Am J Epidemiol. 2016; 84:884-893.

27. Ma H, Wang Y, Sullivan-Halley J, et al. Use of four biomarkers to evaluate the risk of breast cancer subtypes in the women's contraceptive and reproductive experiences study.

Cancer Res. 2010; 70:575-587.

28. Tamimi RM, Colditz GA, Hazra A, et al. Traditional breast cancer risk factors in relation to molecular subtypes of breast cancer. Breast Cancer Res Treat. 2012; 131:159-167.

29. Ghana Statistical Service (GSS) GHSG, and ICF. Ghana Maternal Health Survey 2017. In: Accra GG, GHS, and ICF, editor. Rockville, MD: Department of Health Services ICF; 2018. 
30. Service GS. Ghana Multiple Indicator Cluster Survey with an Enhanced Malaria Module and Biomarker, 2011, Final Report. Accra, Ghana; 2011.

31. Dickens C, Duarte R, Zietsman A, et al. Racial comparison of receptor-defined breast cancer in Southern African women: subtype prevalence and age-incidence analysis of nationwide cancer registry data. Cancer Epidemiol Biomarkers Prev. 2014; 23:2311-2321.

32. Clarke CA, Keegan TH, Yang J, et al. Age-specific incidence of breast cancer subtypes: understanding the black-white crossover. J Natl Cancer Inst. 2012; 104:1094-1101. 33. Collaborative Group on Hormonal Factors in Breast C. Menarche, menopause, and breast cancer risk: individual participant meta-analysis, including 118964 women with breast cancer from 117 epidemiological studies. Lancet Oncol. 2012; 13:1141-1151.

34. Cheng G, Buyken AE, Shi L, et al. Beyond overweight: nutrition as an important lifestyle factor influencing timing of puberty. Nutr Rev. 2012; 70:133-152. 


\section{Figure legends}

Fig. 1: Details of cases and controls for analysis of reproductive factors and breast cancer risk by tumor characteristics in the Ghana Breast Health Study

Intrinsic-like subtype distribution for cases with immunohistochemical data on ER, PR, and HER2 defined as luminal A-like (ER+ or PR+ and HER2-), luminal B-like (ER+ or PR+ and HER2+), HER2-enriched-like (ER- or PR- and HER2+), or triple-negative/basal-like (ER-, PR- and HER2-).

Fig. 2: Temporal trends of menstrual and reproductive risk factors for cases and controls in the Ghana Breast Health Study by birth cohorts from 1945 to 1975

(A) Age at menarche, (B) parity, (C) age at first birth and (D) median breastfeeding months per pregnancy. The means and standard deviations plotted are the results of a 3-point running average. Gray indicates standard deviation.

Fig. 3: ORs and 95\% CIs for joint effects of parity and breastfeeding (vs nulliparous) by ER status and age of onset

Polytomous logistic regression models were used to calculate ORs and 95\% CI, adjusted for age, education, study site, body size, family history of breast cancer, age at menarche, age at first birth, menopausal status, and age at menopause. Error bars indicate standard deviations $=$ breastfeeding. $\mathrm{ER}=$ Estrogen receptor. 
medRxiv preprint doi: https://doi.org/10.1101/19006833; this version posted November 27, 2019. The copyright holder for this preprint (which was not certified by peer review) is the author/funder, who has granted medRxiv a license to display the preprint in perpetuity.

This article is a US Government work. It is not subject to copyright under 17 USC 105 and is also made available for use under a CCO license.

Table 1. Demographic and reproductive characteristics of 1,126 diagnosed invasive breast cancer cases and 2,106 controls from the Ghana Breast Health Study

\begin{tabular}{|c|c|c|c|c|}
\hline & $\begin{array}{l}\text { Controls } \\
\mathrm{N}=\mathbf{2 , 1 0 6}\end{array}$ & & $\begin{array}{l}\text { Cases } \\
\mathrm{N}=1,126\end{array}$ & \\
\hline Study Population Characteristics & $\mathbf{N}$ & $\%$ & $\mathbf{N}$ & $\%$ \\
\hline \multicolumn{5}{|l|}{ Age (years) } \\
\hline$<35$ & 435 & 21 & 114 & 10 \\
\hline $35-44$ & 561 & 27 & 277 & 25 \\
\hline $45-55$ & 554 & 26 & 330 & 29 \\
\hline$\geq 55$ & 546 & 26 & 401 & 36 \\
\hline Unknown & 10 & & 4 & \\
\hline \multicolumn{5}{|l|}{ Study site } \\
\hline Accra & 736 & 35 & 384 & 34 \\
\hline Kumasi & 1370 & 65 & 742 & 66 \\
\hline \multicolumn{5}{|l|}{ Age at menarche (years) } \\
\hline Median age at menarche (IQR) & $15(15-15)$ & & $15(15-15)$ & \\
\hline$<15$ & 568 & 30 & 266 & 27 \\
\hline 15 & 548 & 29 & 255 & 26 \\
\hline 16 & 383 & 20 & 223 & 23 \\
\hline$\geq 17$ & 395 & 21 & 228 & 23 \\
\hline Unknown & 212 & & 154 & \\
\hline \multicolumn{5}{|l|}{ Parity } \\
\hline Median parity (IQR) & $4(2-5)$ & & $3(2-5)$ & \\
\hline Nulliparous & 228 & 11 & 107 & 10 \\
\hline $1-2$ & 533 & 25 & 319 & 28 \\
\hline $3-4$ & 685 & 33 & 365 & 33 \\
\hline$\geq 5$ & 652 & 31 & 331 & 30 \\
\hline Unknown & 8 & & 4 & \\
\hline \multicolumn{5}{|l|}{ Age at first birth (years) } \\
\hline Median age (IQR) & $20(18-24)$ & & $21(19-25)$ & \\
\hline$<19$ & 555 & 31 & 235 & 25 \\
\hline $19-21$ & 510 & 28 & 265 & 28 \\
\hline $22-25$ & 412 & 23 & 260 & 27 \\
\hline$\geq 26$ & 322 & 18 & 197 & 21 \\
\hline Unknown & 79 & & 62 & \\
\hline \multicolumn{5}{|c|}{ Median breastfeeding per pregnancy (months) } \\
\hline Median months(IQR) & $18(15-24)$ & & $18(12-24)$ & \\
\hline$<13$ & 352 & 20 & 239 & 26 \\
\hline $13-18$ & 692 & 39 & 341 & 37 \\
\hline$\geq 19$ & 747 & 42 & 347 & 37 \\
\hline Unknown & 87 & & 92 & \\
\hline \multicolumn{5}{|l|}{ ER status } \\
\hline Positive & & & 393 & 50 \\
\hline Negative & & & 387 & 50 \\
\hline Unknown & & & 346 & \\
\hline
\end{tabular}

PR status 
medRxiv preprint doi: https://doi.org/10.1101/19006833; this version posted November 27, 2019. The copyright holder for this preprint (which was not certified by peer review) is the author/funder, who has granted medRxiv a license to display the preprint in perpetuity.

This article is a US Government work. It is not subject to copyright under 17 USC 105 and is also made available for use under a CCO license.

Positive

Negative

Unknown

\section{HER2 status}

Positive

Negative

Inconclusive

Unknown
402

374

350

181

544

54

347
52

48

23

70

7

$\mathrm{IQR}=$ interquartile range. $\mathrm{ER}=$ estrogen receptor. $\mathrm{PR}=$ progesterone receptor. $\mathrm{HER} 2=$ human epidermal growth factor receptor 2 
Table 2. ORs and 95\% CIs for select reproductive risk factors and breast cancer risk overall, stratified by women younger and older than 50 years among 1,122 cases and 2,096 controls

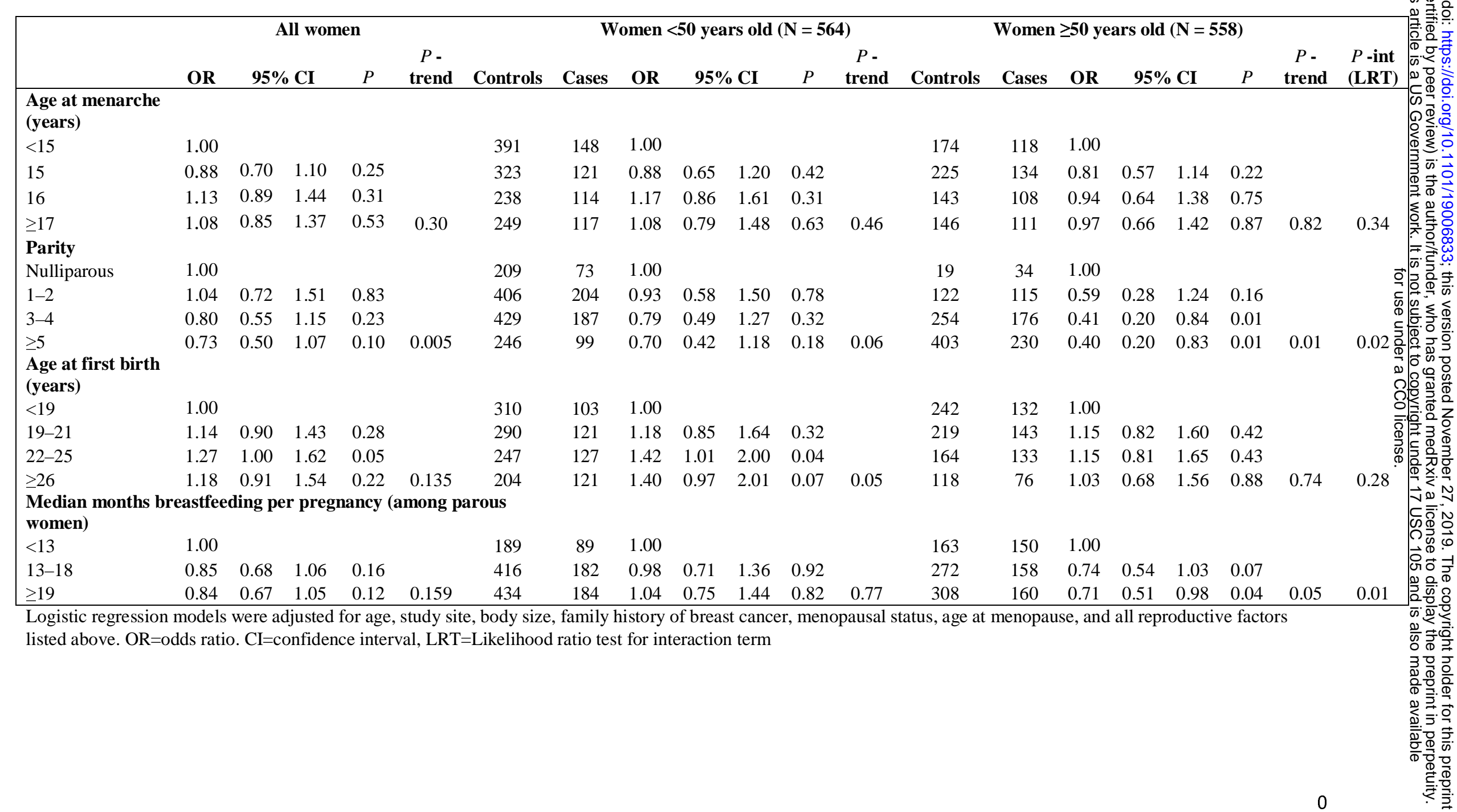


Table 3. Reproductive risk factors and breast cancer risk stratified by ER status among women <50 years of age among 378 cases and 1,294 controls

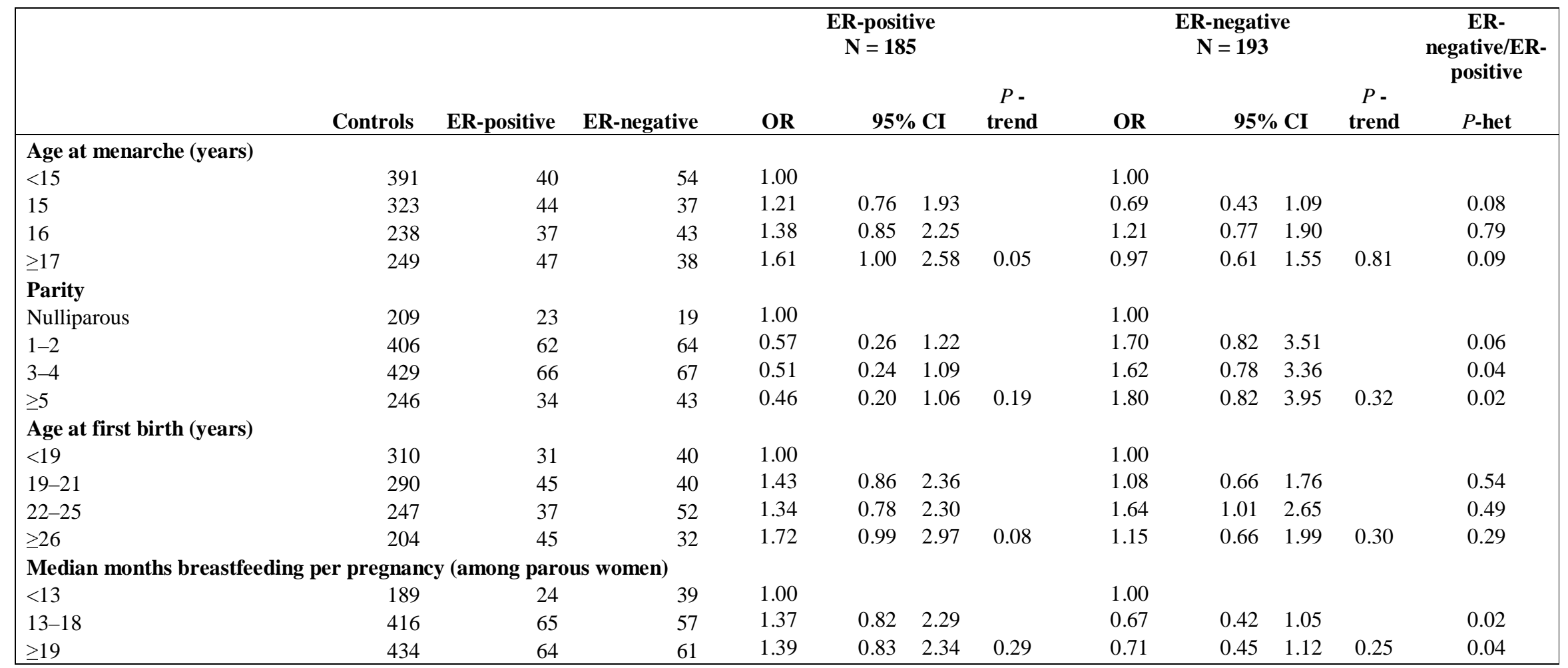

Polytomous logistic regression models were adjusted for age, education, study site, body size, family history of breast cancer, menopausal status, and all reproductive factors listed above. $\mathrm{ER}=$ estrogen receptor. $\mathrm{OR}=$ odds ratio. $\mathrm{CI}=$ confidence interval. $P$-het $=P$-heterogeneity test 
Table 4. Risk factor associations stratified by ER status among women $\geq 50$ years of age among 398 cases and 802 controls

\begin{tabular}{|c|c|c|c|c|c|c|c|c|c|c|c|c|}
\hline & \multirow[b]{2}{*}{ Controls } & \multirow[b]{2}{*}{ ER-positive } & \multirow[b]{2}{*}{ ER-negative } & \multicolumn{4}{|c|}{$\begin{array}{c}\text { ER-positive } \\
N=205\end{array}$} & \multicolumn{4}{|c|}{$\begin{array}{c}\text { ER-negative } \\
\mathbf{N}=193\end{array}$} & \multirow{2}{*}{$\begin{array}{c}\text { ER- } \\
\text { negative/ER- } \\
\text { positive } \\
P \text {-het }\end{array}$} \\
\hline & & & & OR & \multicolumn{2}{|c|}{$95 \% \mathrm{CI}$} & $\begin{array}{c}P- \\
\text { trend }\end{array}$ & OR & \multicolumn{2}{|c|}{$95 \% \mathrm{CI}$} & $\begin{array}{c}P- \\
\text { trend }\end{array}$ & \\
\hline$<15$ & 177 & 51 & 39 & 1.00 & & & & 1.00 & & & & \\
\hline 15 & 225 & 50 & 46 & 0.69 & 0.43 & 0.85 & & 0.85 & 0.51 & 1.39 & & 0.60 \\
\hline 16 & 145 & 37 & 27 & 0.73 & 0.43 & 0.69 & & 0.69 & 0.39 & 1.22 & & 0.84 \\
\hline$\geq 17$ & 146 & 42 & 43 & 0.84 & 0.50 & 1.13 & 0.74 & 1.13 & 0.67 & 1.92 & 0.77 & 0.36 \\
\hline \multicolumn{13}{|l|}{ Parity } \\
\hline Nulliparous & 19 & 12 & 14 & 1.00 & & & & 1.00 & & & & \\
\hline $1-2$ & 127 & 48 & 36 & 0.82 & 0.31 & 2.16 & & 0.34 & 0.13 & 0.88 & & 0.13 \\
\hline $3-4$ & 256 & 72 & 53 & 0.58 & 0.23 & 1.49 & & 0.23 & 0.09 & 0.57 & & 0.83 \\
\hline$\geq 5$ & 406 & 76 & 91 & 0.49 & 0.19 & 1.26 & 0.24 & 0.28 & 0.11 & 0.70 & 0.004 & 0.33 \\
\hline \multicolumn{13}{|c|}{ Age at first birth (years) } \\
\hline$<19$ & 245 & 46 & 50 & 1.00 & & & & 1.00 & & & & \\
\hline $19-21$ & 220 & 49 & 56 & 1.10 & 0.67 & 1.78 & & 1.26 & 0.80 & 2.00 & & 0.55 \\
\hline $22-25$ & 165 & 48 & 42 & 1.10 & 0.66 & 1.83 & & 1.06 & 0.64 & 1.75 & & 1.00 \\
\hline$\geq 26$ & 118 & 32 & 24 & 1.09 & 0.61 & 1.93 & 0.72 & 1.02 & 0.57 & 1.84 & 0.95 & 0.84 \\
\hline \multicolumn{13}{|c|}{ Median months breastfeeding per pregnancy (among parous women) } \\
\hline$<13$ & 163 & 68 & 42 & 1.00 & & & & 1.00 & & & & \\
\hline $13-18$ & 276 & 54 & 53 & 0.61 & 0.39 & 0.95 & & 0.81 & 0.50 & 1.30 & & 0.35 \\
\hline$\geq 19$ & 313 & 51 & 66 & 0.54 & 0.34 & 0.85 & 0.01 & 0.89 & 0.56 & 1.42 & 0.82 & 0.07 \\
\hline
\end{tabular}

Polytomous logistic regression models were adjusted for age, education, study site, body size, family history of breast cancer, menopausal status, age at menopause, and all reproductive factors listed above. $\mathrm{ER}=$ estrogen receptor. $\mathrm{OR}=$ odds ratio. $\mathrm{CI}=$ confidence index. $P$-het $=P$-heterogeneity test 

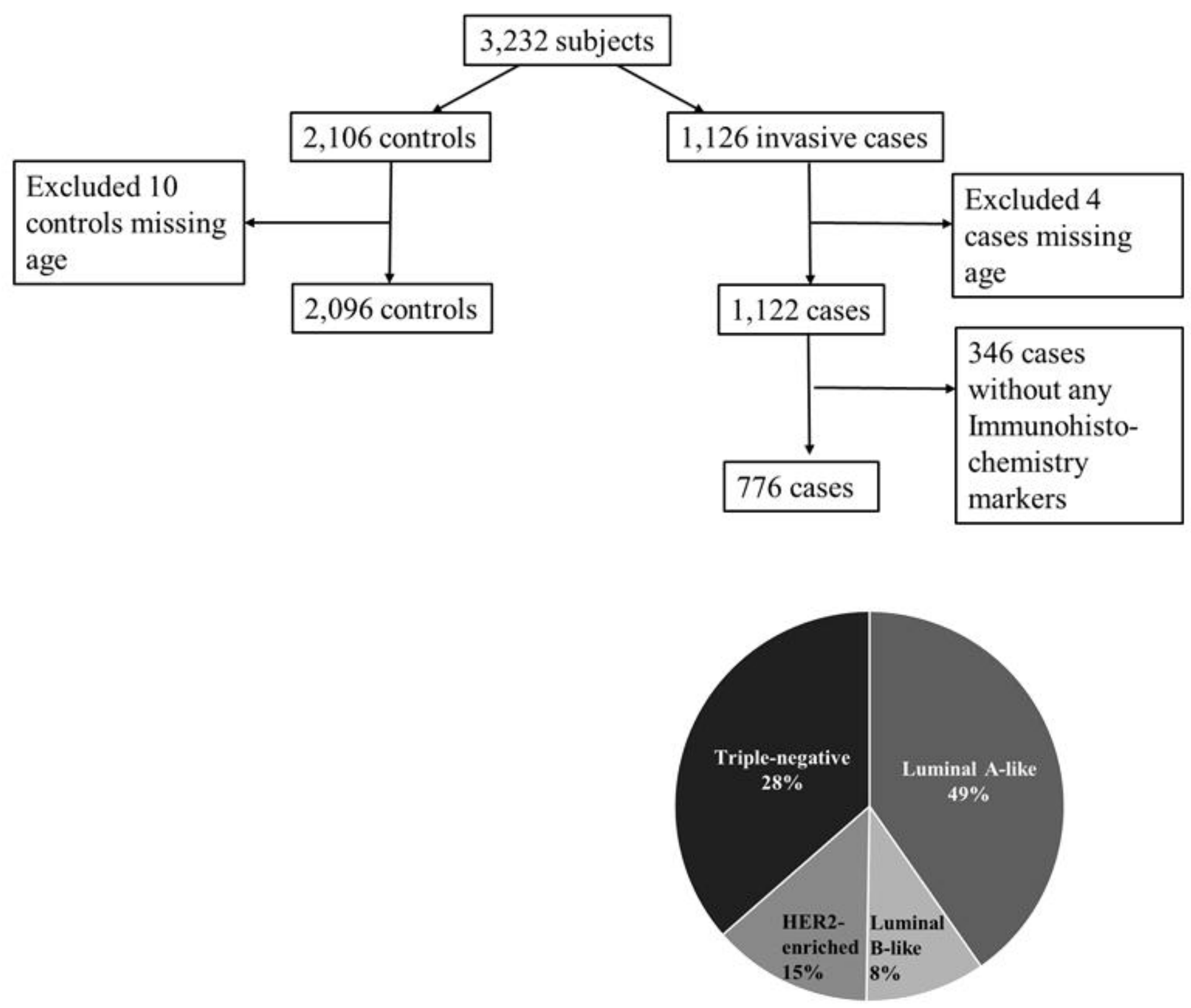
A

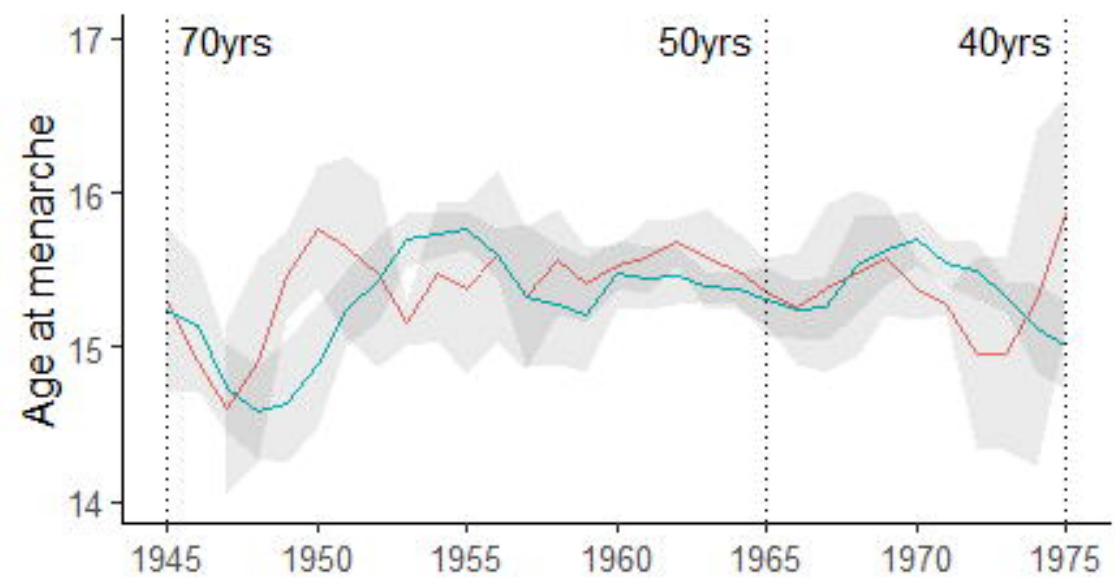

C

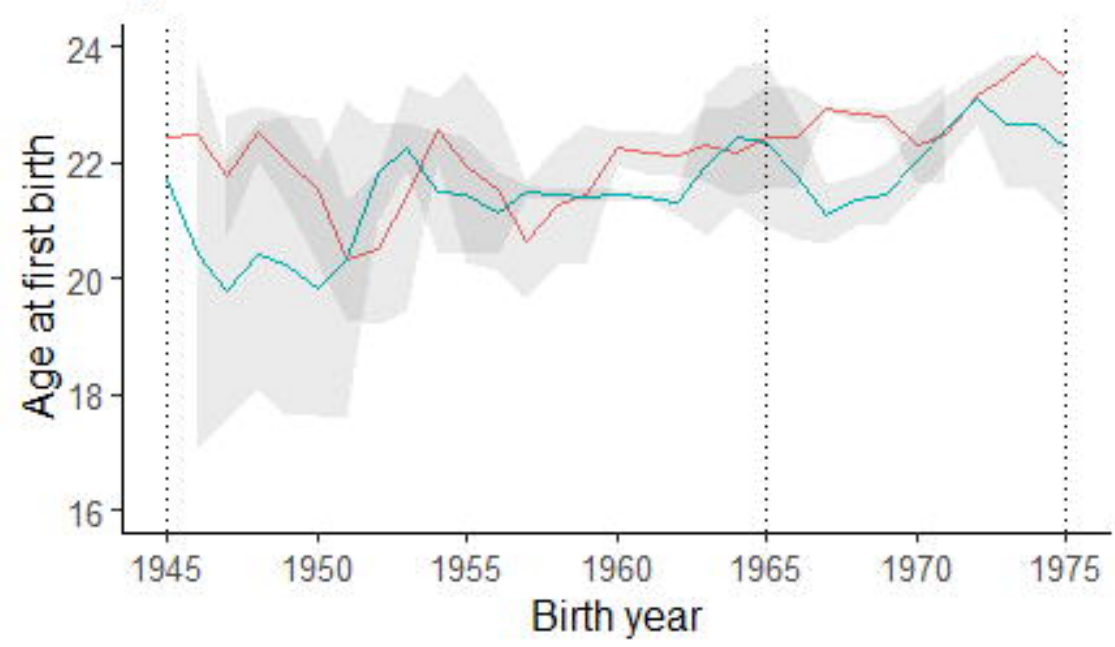

B
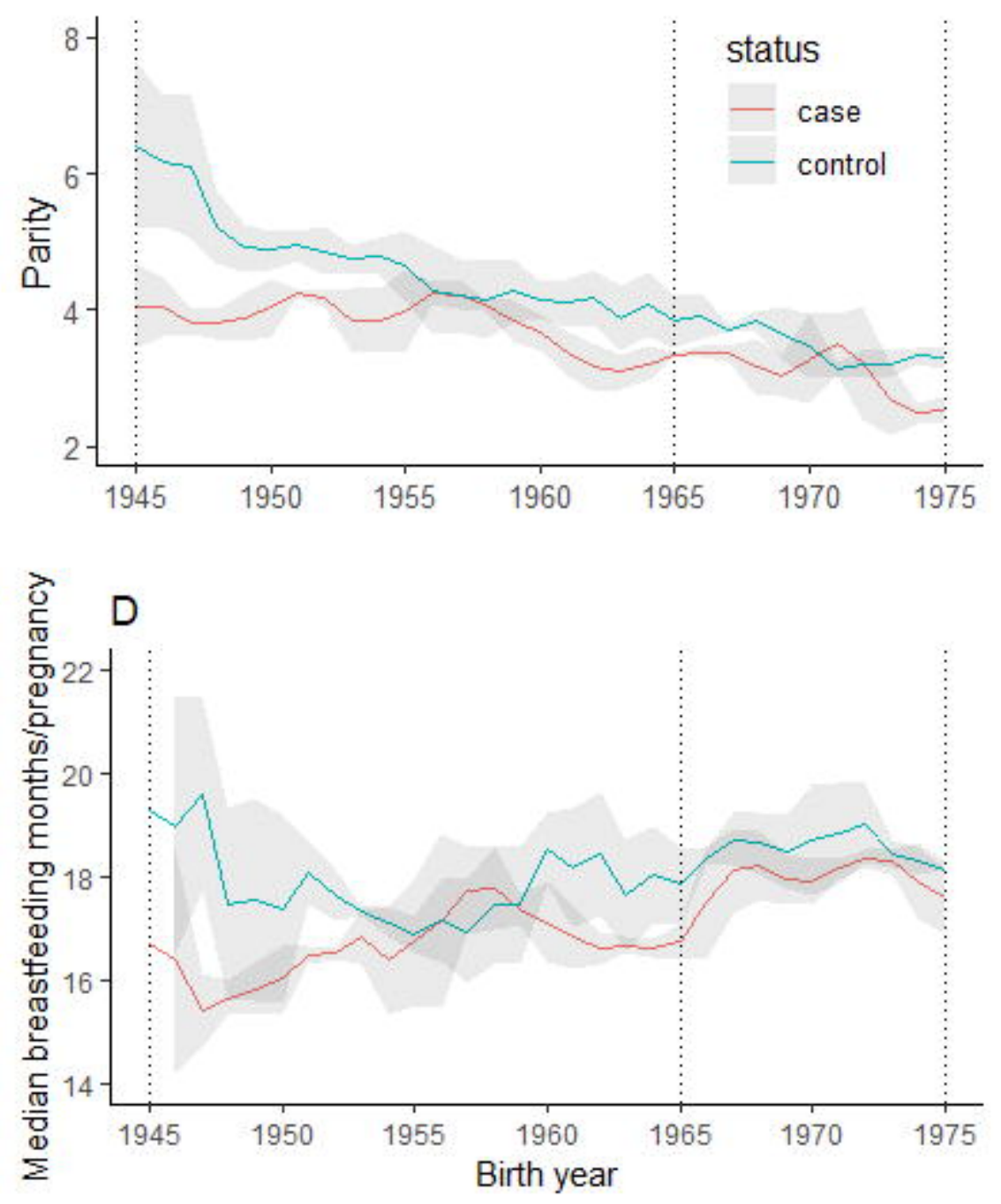


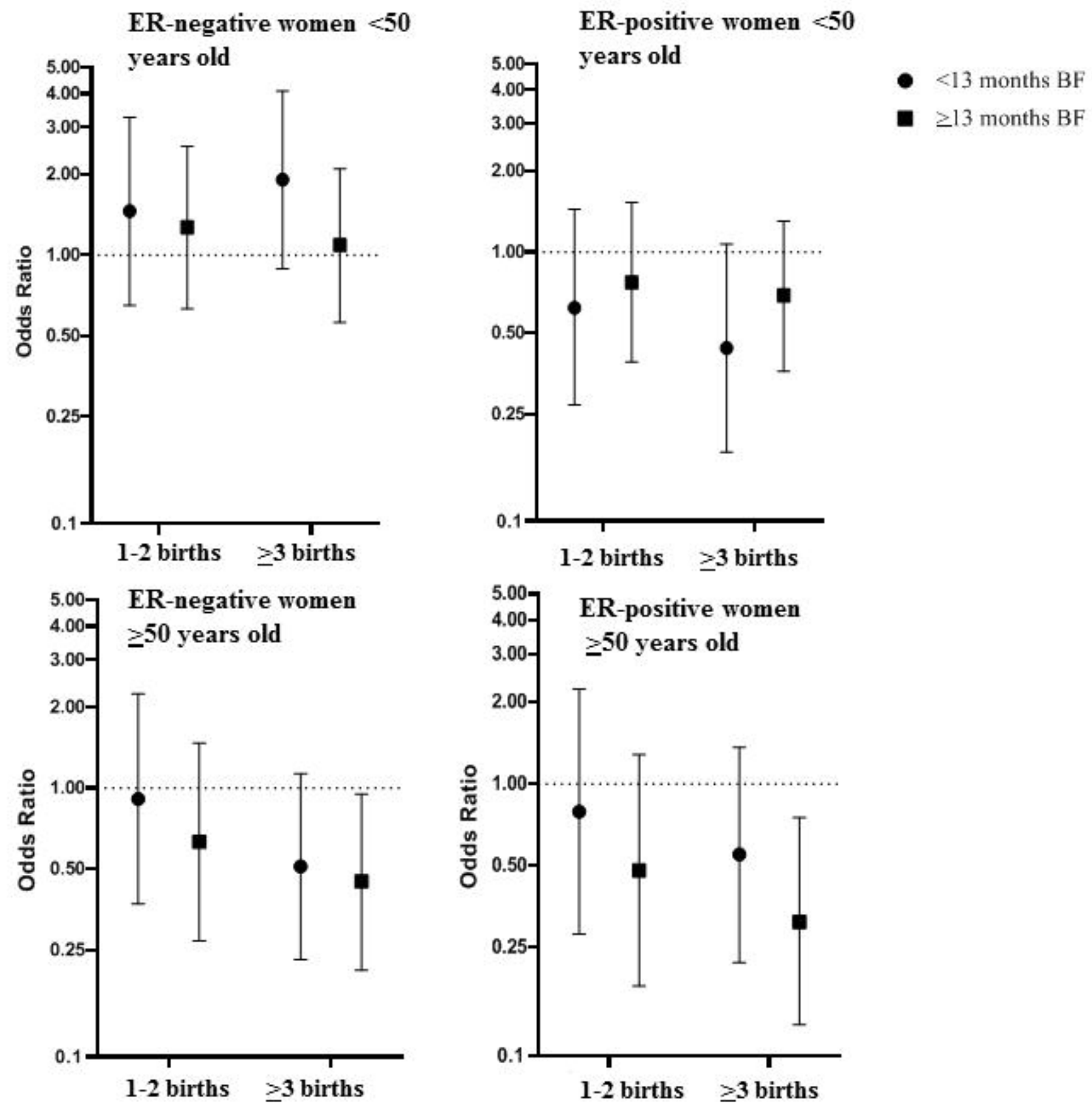

